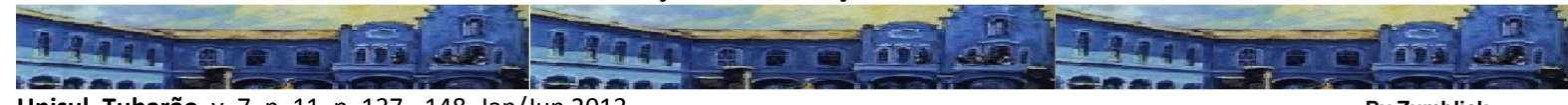

\title{
ABORDAGEM HISTÓRICA E CONTRIBUIÇÕES DO NEAD/UFMA: A EDUCAÇÃO A DISTÂNCIA NO ESTADO DO MARANHÃO
}

\author{
José Augusto Medeiros Silva ${ }^{1}$ \\ Welington Lima Amorim²
}

\begin{abstract}
RESUMO
Historicamente, a Educação a Distância (EaD) foi realizada, a princípio, na Europa, no Brasil e no Maranhão, por correspondência, com a utilização de materiais didáticos enviados pelos Correios e, posteriormente, através do rádio e da televisão. Com o advento das Tecnologias da Informação e Comunicação (TICS), notadamente a partir da década de 1960, os cursos na modalidade a distância passaram a utilizar Ambientes Virtuais de Aprendizagem (AVA) acessados via internet, num processo permanente de interação entre aluno e professor, com acompanhamento através de vídeo-aulas, videoconferências, áudio-conferências, realização de atividades de ensino online e participação em chats e fóruns, dentre outros. Este artigo faz uma abordagem sobre o surgimento e expansão da EaD, sua conceituação, principais características, seus objetivos, sua adoção por Instituições de Ensino Superior (IES), e demonstra a contribuição do Núcleo de Educação a Distância (NEAD/UFMA) à história da educação nesta modalidade no Estado do Maranhão. O presente trabalho é um recorte do Trabalho de Conclusão de Curso elaborado como requisito para a obtenção do grau de especialista em Gestão Pública Municipal.
\end{abstract}

Palavras-chave: Educação à distância; Tecnologia da Informação e Comunicação; Estado do Maranhão.

\section{HISTORICAL APPROACH AND CONTRIBUTIONS OF NEAD/UFMA: DISTANCE LEARNING IN THE STATE OF MARANHÃO}

\begin{abstract}
Historically, Distance Learning (DL) has performed in Europe, Brazil and Maranhão early by correspondence with the use of Post Mail to send teaching materials, and posteriorly through the radio and television. With rising of Information and Communication Technologies (ICTs), especially from 1960s, Distance Courses started using Virtual Learning Environment (VLE), also called Virtual Platform accessed by internet in a continuing process of interaction between student and professor, by attending video classes, videoconferences, audio conferences, and also by carrying out online educational activities and participation in chats and forums, among other. This work presents an approach about the arising and expansion of DL, its conceptualization, main features, goals and its adoption by Higher Education Institutes (HEIs), and demonstrates the contributions of the Center for Distance Learning (CDL/UEMA) to the history of this type of education in the State of Maranhão. This work is part of another one carried out as requirement for obtain the expert degree in Municipal Public Management.
\end{abstract}

Keywords: Distance Learning; Information and Communication Technology; State of Maranhão.

\footnotetext{
${ }^{1}$ Mestrando em Educação - UFMA - E-mail: <joseaugusto_1953@hotmail.com>.

2 Doutor em Ciência Humanas - UFSC - E-mail: <weligton.amorim@gmail.com>.
} 


\section{ABORDAJE HISTÓRICO Y CONTRIBUCIONES DE NEAD/UFMA: LA EDUCACIÓN A DISTANCIA EN EL ESTADO DE MARANHÃO}

\section{RESUMEN}

Históricamente, la Educación a Distancia (EaD) fue realizada, en principio, en Europa, Brasil y en Estado de Maranhão con la utilización de materiales didácticos enviados por correo, y en posterior a través de radio y televisión. Con el surgimiento de las Tecnologías de Información y Comunicación (TICS), principalmente de la década de 1960, los cursos en la modalidad a distancia empezaron a Ambientes Virtuales de Aprendizaje (AVA) con acceso por medio de la internet, en un proceso permanente de interacción entre alumno y profesor, con acompañamiento a través de video clases, videoconferencias, audioconferencias, realización de actividades de enseño online y por participación en chats y fórums, entre otros. Este trabajo hace un abordaje acerca del surgimiento y expansión de la EaD, su conceptuación, principales características, sus objetivos, su uso por Instituciones de Enseño Superior (IES), y demuestra la contribución del Núcleo de Educación a Distancia (NEAD/UFMA) al historia da la educación en esta modalidad en Estado de Maranhão. Este estudio es parte de un Trabajo Final de Curso realizado como exigencia para obtener el grado de especialista en Gestión Pública Municipal.

Palabras-clave: Educación a Distancia; Tecnología de Información y Comunicación; Estado de Maranhão.

Introdução

A Educação a Distância (EaD) surge em 1728, inicialmente com a oferta de material didático impresso e através de cursos por correspondência. Posteriormente, com o advento das Tecnologias da Informação e Comunicação (TICs), o ensino a distância se moderniza e sua utilização torna-se cada vez maior em todo o mundo. As TICs correspondem a um conjunto de recursos tecnológicos integrados que possibilitam, por meio das funções de hardware e software, a automação e comunicação dos processos de negócios, da pesquisa científica e de ensino e aprendizagem. As TICs têm contribuíndo como eficiente recurso na era da geração digital para a modernização do processo educacional. Em São Luís, capital do Estado do Maranhão, há escolas que substituíram os livros e cadernos por Tablets pelo fato de possibilitarem o aceso às Bibliotecas virtuais para realização de pesquisas, exercícios e informações em tempo real. Para Bruner (1996), “o horizonte de uma criança, hoje em dia, ultrapassa claramente o limite físico da sua escola, da sua cidade ou do seu país, quer se trate do horizonte cultural, social, pessoal ou profissional". (BRUNER, 1996, p. 115).

O presente trabalho tem por objetivo investigar a gênese da educação a distância, sua evolução e organicidade, institucionalização e prática por universidades na 
José Augusto Medeiros Silva Welington Lima Amorim

Europa, no Brasil e no Estado do Maranhão. Enfatiza a criação da Open University (Universidade Aberta) em 1969, na Inglaterra, reconhecida como marco no Ensino Superior a distância. Também explicita a trajetória cronológica dos marcos da EaD no Brasil e está subsidiado com referencial sobre a temática, de autores como Dohmem (1967), Peters (1973), Chaves (1999), entre outros, bem como da análise de relatórios e publicações do NEAD/UFMA sobre as ações desenvolvidas através dos Polos UAB e Campi da UFMA no período de 2007 a 2012, além de descrever as contribuições do NEAD/UFMA para a história da EaD no Estado do Maranhão.

\section{Educação a Distância - EaD}

Segundo Dohmem (1967), Educação a Distância (Ferstudium):

[...] é uma forma sistematicamente organizada de auto-estudo através do qual o aluno se instrui a partir do material de estudo que lhe é apresentado. O acompanhamento e a supervisão do sucesso do estudante são acompanhados por um grupo de professores. Isto é possível ser feito por meios de comunicação tais como: o Rádio e a Televisão, TV a cabo (CATV), Satélites de Transmissão Direta (DBS - Direct Broadcast Satellites), Vídeo transmissão, Teleconferência, Áudio-conferência, Vídeo-conferência (ITV Interactive Television), etc. (DOHMEM, 1967).

Vale ressaltar que foi a partir da utilização das TICs, através dos mais variados meios acima mencionados, que o ensino a distância se expandiu rapidamente a todas as regiões do planeta, propiciando o acesso, a democratização do ensino e, consequentemente, a inclusão. Para Peters (1973), a educação/ensino a distância (Fernunterricth),

[...] é um método racional de partilhar conhecimento, habilidades e atitudes, através da aplicação da divisão do trabalho e de princípios organizacionais, tanto quanto pelo uso extensivo de meios de comunicação, especialmente para o propósito de reproduzir materiais técnicos de alta qualidade, os quais tornam possível instruir um grande número de estudantes ao mesmo tempo [...]. É uma forma industrializada de ensinar e aprender. (PETERS, 1973).

O autor supramencionado destaca o aspecto da prática do processo de ensinoaprendizagem com a utilização das TICs, em especial no que diz respeito à disponibilidade de material didático e à interatividade na resolução de atividades escolares, atingindo grande 
contingente de alunos nas mais diversas localidades, ao mesmo tempo. Finalizando, Chaves (1999) conclui que a EaD, no sentido fundamental da expressão,

[...] é o ensino que ocorre quando o docente e o discente estão separados (no tempo ou no espaço). No sentido que a expressão assume hoje, enfatiza-se mais a distância no espaço e se propõe que ela seja contornada através do uso de tecnologias de telecomunicação e de transmissão de dados, voz e imagens (incluindo dinâmicas, isto é, televisão ou vídeo). Não sendo necessário ressaltar que todas essas tecnologias, hoje, convergem para o computador. (CHAVES, 1999).

No âmbito da legislação, o Ministério da Educação e Cultura - MEC, através do Decreto Lei № 5.622/2005, conceitua a EaD da seguinte forma:

Caracteriza-se a educação a distância como modalidade educacional na qual a mediação didático-pedagógica nos processos de ensinoaprendizagem ocorre com a utilização de meios e tecnologias de informação e comunicação, com estudantes e professores desenvolvendo atividades educativas em lugares ou tempos diversos. (MEC, 2005).

O MEC legaliza o exercício da prática pedagógica do processo ensinoaprendizagem, propiciando, a quem assim o quiser, o aceso à educação. $E$, tendo em vista o crescimento da competitividade para inserção no mercado de trabalho, a educação a distância apresenta-se como opção para a qualificação profissional em praticamente todas as áreas do conhecimento.

\section{Educação a Distância - EaD: características}

A EaD caracteriza-se, segundo Domingo (2010), pela autoinstrução e pela conservação didática guiada e bidirecional, fazendo com que o perfil, o nível e as necessidades do aprendiz norteiem a elaboração do material didático. Descrevem-se, a seguir, algumas das principais características da EaD:

a) Utilização de meios técnicos, ou seja, os recursos de comunicação (impressos, áudios, vídeos, etc.) que estão acessíveis à boa parte da população e possibilita a democratização do acesso a educação;

b) Aprendizagem independente e flexível, em outras palavras, respeita-se a autonomia do aprendiz em relação ao tempo, estilo, ritmo e método de aprendizagem com 
o objetivo de conscientizá-lo de suas capacidades e possibilidades para sua própria formação;

c) Uso de comunicações massivas, isto é, das novas tecnologias da informação e dos modernos meios de comunicação que tornaram possível a recepção de mensagens educativas por grande número de pessoas dispersas geograficamente.

\section{Educação a Distância - EaD: objetivos}

Seguem alguns dos principais objetivos da EaD:

a) Democratizar o acesso à educação;

b) Atendimento aos alunos residentes em locais onde não haja instituições convencionais de ensino;

c) Favorecer uma aprendizagem autônoma e ligada à experiência, o que significa uma formação fora do contexto da sala de aula;

d) Promover uma educação inovadora e de qualidade, com sistema educativo renovador por sua sistemática e recursos didáticos instrucionais e de multimídia.

\section{Abordagem histórica da Educação a Distância}

O marco inicial da educação a distância, de acordo com Peters (2003), foi o anúncio publicado na Gazeta de Boston, no dia 20 de março de 1728, pelo Professor de Taquigrafia Cauleb Phillips, através do qual oferecia material para ensino e tutoria por correspondência. Os primeiros cursos a distância surgiram na Europa, por volta de 1840 . A primeira Escola por correspondência de que se tem conhecimento data de 1890, na Alemanha. A partir de então, vários países adotaram a EaD como opção para ministrar cursos nos níveis médio, técnico, superior e de pós-graduação.

No Continente Europeu, além da Alemanha, inúmeros países destacam-se pela utilização da EaD como formação cultural, dentre os quais França, Itália, Espanha, Bélgica, e Inglaterra, com maior destaque para este último, por ser o primeiro país a criar a Open University (Universidade Aberta) em 1969, reconhecida como marco no Ensino Superior a distância. Gouvêa e Oliveira (2006) e Nunes (2009) relatam, cronologicamente, o surgimento 
das universidades para a oferta exclusiva de EaD. Em 1951, registra-se a Universidade de Sudáfrica; em 1968, a University of the South Pacific; em 1971, a British Open University, referência na oferta de EaD; e em 1972, a Universidad Nacional de Educación a Distancia (UNED).

Especificamente na América Latina, os registros de universidades surgiram no início do século XX. Em 1947, no México e Colômbia, e em 1960, a Tele Escola Primária do Ministério da Cultura e Educação - MCE, na Argentina.

No Brasil não há registros precisos sobre a criação da EaD. Alves (2009) afirma que "estudos realizados pelo Instituto de Pesquisa Econômica Aplicada (IPEA) mostram que, pouco antes de 1900, já existiam anúncios em jornais do Rio de Janeiro que ofereciam cursos profissionalizantes de datilografia, ministrados por professoras particulares". Alguns autores afirmam que a primeira experiência oficial foi em 1904, a partir da implantação das Escolas Internacionais, que representaram organizações norte-americanas. A EaD brasileira seguiu o movimento internacional, com a oferta de cursos por correspondência. Cronologicamente, os principais marcos da Educação a Distância no Brasil são os seguintes:

- Cursos por Correspondência - 1904: o Jornal do Brasil registra um anúncio que oferece profissionalização por correspondência para datilógrafo;

- Rádio-Escola (sic) - 1923: A Fundação Roquette-Pinto cria, neste ano, a Rádio Sociedade do Rio de Janeiro e em 1934 instala a Rádio-Escola Municipal no Rio (sic);

- Instituto Monitor - 1939: ofereceu o primeiro curso por correspondência, de Radiotécnico;

- Instituto Universal Brasileiro - 1941: oferece cursos profissionalizantes e sua principal mídia são apostilas enviadas pelos Correios;

- Projeto Minerva - 1970: o Ministério da Educação e Cultura - MEC, Fundação Padre Lendel de Moura e a Fundação Padre Anchieta celebraram convênio cujo objeto era a utilização de rádio para a educação e a inclusão social de adultos;

- Telecurso - 1977: Cursos Supletivos a Distância começaram a ser oferecidos por fundações privadas e organizações não governamentais, utilizando tecnologias de teleeducação, satélite e materiais impressos; 
- Salto Para o Futuro - 1991: concebido e produzido pela Fundação Roquette Pinto, teve início em 1991. Em 1995 foi incorporado à TV Escola, tornando-se um marco do EaD nacional.

Verifica-se, nos dias atuais, a utilização cada vez mais crescente da Educação a Distância (EaD) como eficiente ferramenta educacional pelas redes de TVs e programas de ensino institucionais, valendo destacar: as redes de televisão educativa, dentre as quais o Canal Futura da Rede Globo de Televisão; a TV Educativa da Fundação Padre Anchieta e a TV Escola do Ministério da Educação e Cultura - MEC, apresentando programas com fins educativos, veiculando atividades inovadoras de aprendizagem e interação. Vale destacar como de extraordinária importância para a EaD no Brasil, a criação, em 1995, da Associação Brasileira de Educação a Distância (ABED - disponível em <http://www2.abed.org.br/>) e a Secretaria de Educação a Distância (SEED/MEC - disponível em <http://portal.mec.gov.br/>), como instituições que promoveram grande impulso na sua organização e desenvolvimento.

No âmbito da legislação, como modalidade de ensino, a Educação a Distância (EaD) no Brasil foi proposta pela Lei n.o 9.394/96, em seu Art. 80, tendo suas diretrizes e metas estabelecidas no Plano Nacional de Educação (PNE) - Lei n. 10.172/2001. Neste plano, a educação a distância é entendida como estratégia de democratização do acesso à educação, especificamente àquela de nível superior, bem como da melhoria dos processos de ensino-aprendizagem, como demonstra o texto do referido plano, a seguir:

No processo de universalização e democratização do ensino, especialmente no Brasil, onde os déficits educativos e as desigualdades regionais são tão elevados, os desafios educacionais existentes podem ter, na educação a distância, um meio auxiliar de indiscutível eficácia. [...] Ao introduzir novas concepções de tempo e espaço na educação, a educação a distância tem função estratégica: contribui para o surgimento de mudanças significativas na instituição escolar e influi nas decisões a serem tomadas pelos dirigentes políticos e pela sociedade civil na definição de prioridades educacionais (FUNADESP, 2005, p. 33).

O Decreto no 5.800 de 2006, publicado no Diário Oficial da União em 09.06.2006, criou o Sistema Universidade Aberta do Brasil - UAB, um programa do Ministério da Educação e Cultura - MEC, com o objetivo de estimular a articulação e integração do sistema nacional de Educação Superior. Este sistema é formado por instituições públicas de Ensino Superior, as quais se comprometem a levar este nível de ensino público e de qualidade aos municípios brasileiros. 


\section{A institucionalização do NEAD/UFMA}

O Núcleo de Educação a Distância (NEAD) é o setor que gere a modalidade de ensino a distância na Universidade Federal do Maranhão (UFMA). Os primórdios deste setor estão ligados diretamente à institucionalização da EaD/UFMA, iniciada em 02 de fevereiro de 2004 através da Resolução n 73/2004, que criou o Núcleo de Tecnologias da Informação, Redes e Educação a Distância (NTIREaD), na época constituído pelas subunidades: Núcleo de Tecnologia de Informação (NTI) e Núcleo de Educação a Distância (NEAD).

No ano de 2006, através da Portaria no 682/2006, do Ministério da Educação e Cultura (MEC), a UFMA foi credenciada para oferta de Educação Superior na modalidade a distância em todo o Estado do Maranhão.

\section{Contribuições DO NEAD/UFMA ao Estado do Maranhão}

O Relatório de Acompanhamento da Educação a Distância do NEAD, na Universidade Federal do Maranhão (UFMA), referente ao período de 2007 a 2012, descreve sucintamente suas contribuições ao Estado do Maranhão.

\section{Locais de Apoio Presencial}

A UFMA possui 30 locais de apoio presencial, sendo 23 Polos da Universidade Aberta do Brasil (UAB) e 7 Campi/UFMA, os quais atendem alunos de 140 municípios.

\section{Cursos Ofertados}

A UFMA ofertou, no período anteriormente mencionado, 28 Cursos na modalidade a distância, sendo 8 de graduação, 10 de pós-graduação e 10 de extensão.

\section{Alunos Matriculados}

O número de alunos matriculados nos cursos a distância oferecidos pelo NEAD/UFMA, no período de 2007 a 2012, foi de 7.223, sendo 909 nos Cursos de Graduação, 3.153 nos Cursos de Pós-Graduação e 3.161 nos Cursos de Extensão. 
Gráfico 1 - Distribuição gráfica dos alunos matriculados nos cursos a distância oferecidos pelo NEAD/UFMA no período de 2007 a 2010

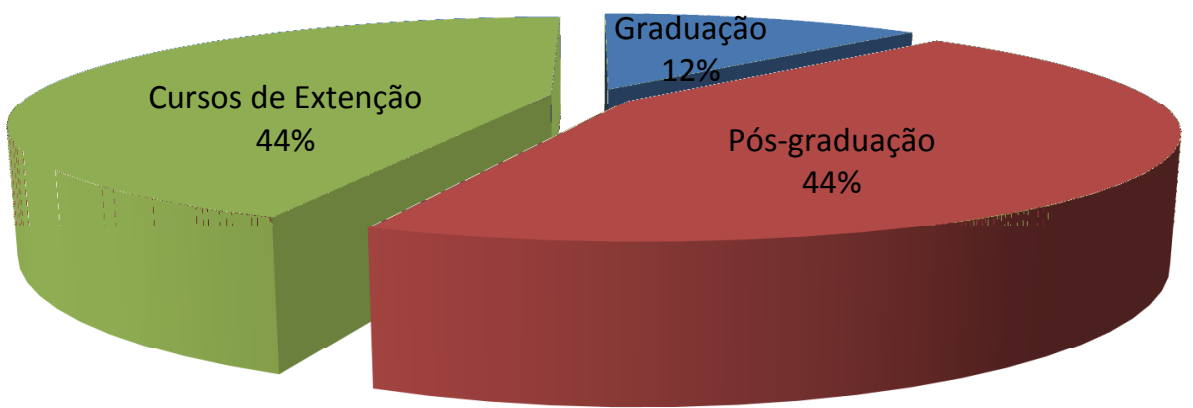

Fonte: SILVA e AMORIM, 2013.

Especificamente o Curso de Especialização em Gestão Pública Municipal (GPM) ofertou 320 vagas distribuídas em 8 Polos UAB/UFMA, nos municípios de Bom Jesus das Selvas, Caxias, Codó, Humberto de Campos, Grajaú, Imperatriz, Pinheiro e Porto Franco. Estes polos propiciaram o acesso à educação como forma de inclusão social e desenvolvimento regional a alunos de 54 municípios do Estado do Maranhão, conforme pode ser vista a distribuição no mapa da página seguinte.

Figura 1 - Distribuição dos 8 Pólos do Curso de GPM no Estado do Maranhão.

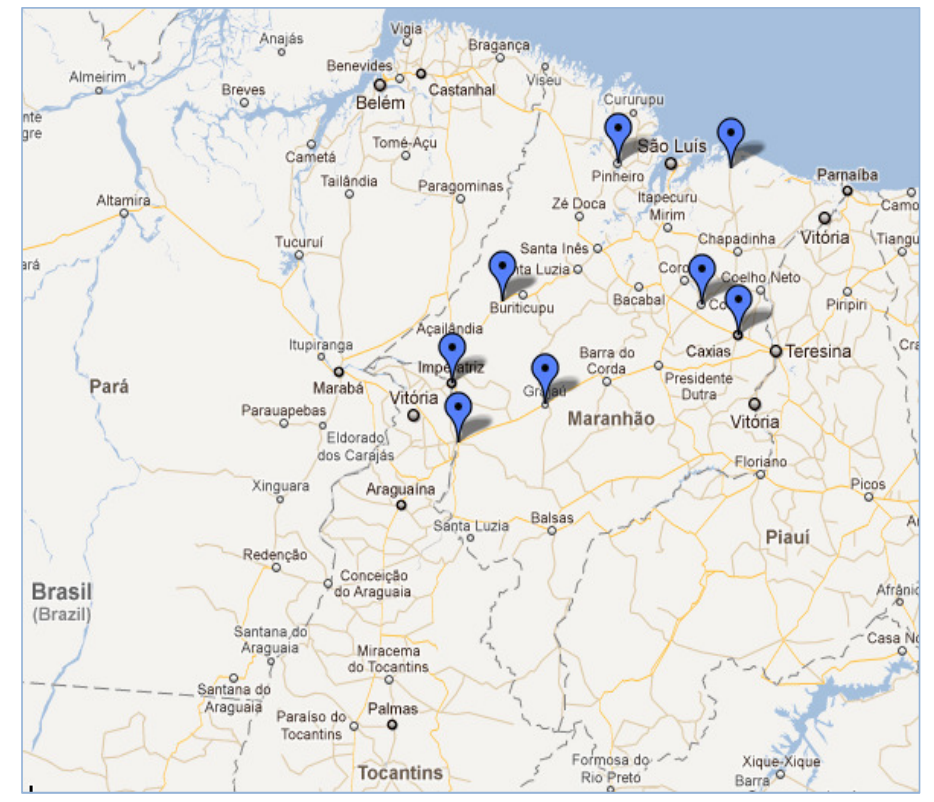

Fonte: C. C. Costa / Google Maps. 


\section{Docentes Capacitados}

Foram capacitados, no período de 2007 a 2012, 721 docentes. A estimativa para o ano de 2013 é de 1000 professores. Se alcançada a meta estimada, o NEAD/UFMA terá capacitado, no período de 2007 a 2013, 1.721 docentes.

\section{Salas Virtuais}

A Coordenação Tecnológica do NEAD/UFMA instalou, no período de 2007 a 2012, 166 Ambientes Virtuais de Aprendizagem AVA e AVAPG, com softwares, suporte técnico, produção multimídia (videoconferências e videoaulas) para atender docentes, discentes e técnicos através de treinamentos e ambientações.

O presente relatório aponta o crescimento do NEAD/UFMA no período de 2007 a 2012, passando de 1 Polo para 23; de 4 Salas Virtuais AVA e AVAPG para 166; de 2 Cursos para 28 e de 823 alunos para 8.135. A estimativa para o ano de 2013 é de 8.100 alunos. Em se confirmando esta estimativa, terá alcançado 16.235 alunos matriculados, o que representa, além de significativo avanço, grande contribuição à educação no Estado do Maranhão.

\section{Considerações Finais}

O presente trabalho não teve a pretensão de esgotar tão vasto tema como a Educação a Distância (EaD), tão pouco pretendeu considerar uma feitura acadêmica acabada. Conforme consta em seu objetivo, realizou-se, através do referencial teórico e da análise de documentos, uma abordagem histórica da EaD, iniciando por sua gênese, em 1728, com o anúncio publicado na Gazeta de Boston, oferecendo material para ensino e tutoria por correspondência, seguida pelo surgimento na Europa, em 1840, dos primeiros cursos a distância e da primeira escola por correspondência de que se tem conhecimento, em 1890, na Alemanha.

A trajetória histórico-cronológica aponta marcos da Educação a Distância no Brasil, que teve início em 1904 com a oferta de cursos profissionalizantes por correspondência, para Datilógrafo, divulgado em anúncio pelo Jornal do Brasil, chegando, 
quase um século depois, no ano de 1991 ao programa Salto Para o Futuro, concebido e produzido pela Fundação Roquette Pinto e, posteriormente, em 1995 incorporado à TV Escola, apontando o significativo avanço desta modalidade educacional e estabelecendo um referencial da EaD nacional.

Destacou-se a criação, em 2006, pelo Ministério da Educação e Cultura (MEC), da Universidade Aberta do Brasil (UAB), sistema que propiciou às Instituições Federais de Ensino Superior (IFES), inclusive à UFMA, grande avanço na democratização do acesso à educação, e a consequente inclusão digital na era do conhecimento, que habilita para inserção no competitivo mercado de trabalho globalizado.

Enfatiza-se a importância da educação a distância como modalidade educacional alternativa para aqueles que, por insuficiência de vagas nas escolas de ensino convencional, em especial nos cursos de graduação e pós-graduação, tenham a oportunidade de prosseguir em seus estudos de nível superior para, então, poderem competir nesta sociedade do conhecimento do mundo globalizado.

Salienta-se que o Estado do Maranhão, segundo o IPEA e Instituto Brasileiro de Geografia e Estatística (IBGE), é um dos mais pobres da federação e, em alguns municípios da Região dos Cocais, o índice de analfabetismo chega a 68\%. O NEAD/UFMA, segundo Relatório do ano de 2012, leva a Educação, por meio de cursos de extensão, de graduação e pós-graduação, através dos Polos UAB e Campi UFMA, a mais de $75 \%$ dos municípios maranhenses, prestando relevante contribuição à história da educação deste estado.

Acredita-se, por fim, que o NEAD/UFMA, com os investimentos feitos em 2012 na aquisição de modernos equipamentos com tecnologia de ponta e equipe de profissionais qualificados e comprometidos com a excelência do processo ensino-aprendizagem, tenha total possibilidade de expandir com qualidade a oferta de cursos na modalidade a distância em todos os Polos UAB e Campi UFMA, contribuindo significativamente para a história desta modalidade de educação no Estado do Maranhão.

\section{Referências}

ALVES, João Roberto. A história da EaD no Brasil. In: LITTO, Fredric; FORMIGA, Marcos. Educação à distância. $O$ estado da arte. São Paulo: Pearson Education do Brasil, 2009. p. 913. 
. Associação Brasileira de Educação a Distância - ABED. Disponível em:

<http://www2.abed.org.br/.> Acesso em: 17 Outubro 2011.

BRASIL. Presidência da República. Lei no 9.394/1996. Lei de Diretrizes e Bases da Educação Nacional (LDB). Brasília: Ministério da Educação, 1996.

BRASIL. Presidência da República. Lei no no 10.172/2001. Plano Nacional de Educação (PNE). Brasília: Ministério da Educação, 2001.

BRASIL. Presidência da República. Decreto Lei № 5.622, 2005. Regulamenta o art. 80 da Lei № 9.394/1996, que estabelece as diretrizes e bases da educação nacional (Educação a Distância). Brasília: Ministério da Educação, 2005.

BRASIL. Presidência da República. MEC. Decreto Lei № 5.800/2006. Universidade Aberta do Brasil. Sobre Educação a Distância. Disponível em: <http://www.uab.mec.gov.br. $>$ Acesso em: 17 Outubro 2011.

CHAVES, E. Conceitos Básicos: Educação a Distância. EdutecNet: Rede de Tecnologia na Educação, 1999. Disponível em: <http://www.edutecnet.com.br/.> Acesso em: 17 Outubro 2011.

Didática do ensino à distância: Experiências e estágio da discussão numa visão internacional. São Leopoldo: Editora Unisinos, 2003.

DOMINGO, Reinaldo Portal (org). Fomento para TICs na Educação. Revista do NEAD, Volume 1, p. 13-16. São Luís: 2010.

FUNDAÇÃO NACIONAL DE DESENVOLVIMENTO DO ENSINO SUPERIOR PARTICULAR (FUNADESP). Legislação e normas da educação a distância no Brasil. Brasília: Funadesp, 2005.

GOUVÊA, Guaracira; OLIVEIRA, Carmem Irene. Educação a Distância na formação de professores: viabilidade, potencialidades e limites. Rio de Janeiro: Vieira \& Lent, 2006. KEEGAN, D. Bases de Educação à Distância. 2. Ed. Londres: Routledge, 1991.

. Ministério da Educação e Cultura - MEC. Secretaria de Educação a Distância SEED/MEC. Disponível em: <http://portal.mec.gov.br/.> Acesso em: 17 Outubro 2011.

NUNES, Ivônio B. A história da EaD no mundo. In: LITTO, Fredric; FORMIGA, Marcos. Educação à distância: o estado da arte. São Paulo: Pearson Education do Brasil, 2009, p. 2-8.

PETERS, O. A educação à distância em transição: tendências e desafios. São Leopoldo: Editora Unisinos, 2003. 
ABORDAGEM HISTÓRICA E CONTRIBUIÇÕES DO NEAD/UFMA

José Augusto Medeiros Silva Welington Lima Amorim

Relatório de Acompanhamento da Educação a Distância - EaD na Universidade Federal do Maranhão - UFMA. 2007 a 2012.

RECEBIDO EM 12 DE ABRIL DE 2013.

APROVADO EM 13 DE JUNHO DE 2013. 